\title{
Meat consumption and risk of type 2 diabetes: the Multiethnic Cohort
}

\author{
A Steinbrecher ${ }^{1}$, E Erber $^{1}$, A Grandinetti ${ }^{2}$, LN Kolonel ${ }^{1}$ and $G$ Maskarinec ${ }^{1, *}$ \\ ${ }^{1}$ Cancer Research Center, University of Hawaii, 1236 Lauhala Street, Honolulu, HI 96813, USA: \\ ${ }^{2}$ John A. Burns School of Medicine, University of Hawaii, Honolulu, HI, USA
}

Submitted 20 March 2010: Accepted 1 June 2010: First published online 13 July 2010

\begin{abstract}
Objective: To examine the association of meat consumption with diabetes risk in the Hawaii component of the Multiethnic Cohort and to assess effect modification by ethnicity.

Design: A prospective cohort study. Baseline information on diet and lifestyle was assessed by questionnaire. The cohort was followed up for incident cases of diabetes, which were identified through self-reports, medication questionnaires, or health plan linkages. Cox regression was used to calculate hazard ratios (HR) and 95\% confidence intervals for diabetes associated with quintile of meat consumption.

Setting: Hawaii, USA.

Subjects: A total of 29759 Caucasian, 35244 Japanese-American and 10509 Native Hawaiian men and women, aged $45-75$ years at baseline.

Results: During a mean follow-up time of 14 years, 8587 incident diabetes cases were identified. Intake of red meat was positively associated with diabetes risk in men (fifth $v$. first quintile: $\mathrm{HR}=1 \cdot 43 ; 95 \% \mathrm{CI} 1 \cdot 29,1 \cdot 59$ ) and women (fifth $v$. first quintile: $\mathrm{HR}=1 \cdot 30 ; 95 \% \mathrm{CI} 1 \cdot 17,1 \cdot 45)$ in adjusted models. The respective HR for processed red meat intake were 1.57 (95\% CI 1.42, 1.75) and 1.45 (95\% CI 1.30, 1.62). The association for processed poultry was weaker than for processed red meat, and fresh poultry intake was not associated with diabetes risk. For men only, we observed significant interactions of ethnicity with the red and processed red meat associations, with Caucasians experiencing slightly higher risks than Japanese-Americans.

Conclusions: Our findings support the growing evidence that red and processed meat intake increase risk for diabetes irrespective of ethnicity and level of BMI.
\end{abstract}

Keywords
Type 2 diabetes
Meat
Ethnicity
Prospective study

The prevalence of type 2 diabetes mellitus is increasing worldwide; however, some ethnic groups, such as AsianAmericans or Pacific Islanders, suffer from extremely high rates compared with Caucasians ${ }^{(1)}$. In the Multiethnic Cohort (MEC), diabetes incidence rates of $15 \cdot 5$, 12.5 and 5.8 per 1000 person-years were found for Native Hawaiians, Japanese-Americans and Caucasians, respectively $^{(2)}$. A higher BMI and lower education were associated with higher incidence rates. Established risk factors for diabetes are overweight, obesity and physical inactivity $^{(3)}$; still, dietary factors might play an important role. A meta-analysis on meat intake and diabetes risk concluded that particularly red meat and processed meat increase diabetes risk ${ }^{(4)}$. Thus far, no prospective study has examined whether this association is modified by ethnicity. We examined the association of meat consumption (red meat, processed red meat, fresh poultry and processed poultry) with diabetes risk in men and women of Caucasian, Japanese-American and Native Hawaiian ancestry in the Hawaii component of the MEC.

\section{Materials and methods}

\section{Study population}

The MEC was designed to investigate the association between diet and cancer among different ethnic groups in Hawaii and California and detailed information on study design and recruitment can be found elsewhere ${ }^{(5)}$. In brief, between 1993 and 1996, more than 215000 men and women, aged 45-75 years at recruitment, enrolled by completing a mailed questionnaire on diet, demographics, medical conditions, anthropometric measures and lifestyle factors.

The Hawaiian component of the MEC comprises 103898 participants, primarily Caucasians, Japanese-Americans and Native Hawaiians. Response rates ranged from $28 \%$ to $51 \%$ in the different ethnic-sex groups, and comparison with US Census data indicated that the study population represented all levels of education. For the present analysis, subjects belonging to other ethnicities ( $n$ 8797), prevalent diabetes cases ( $n$ 10028) and unconfirmed cases ( $n$ 812) were 
excluded, as were subjects with missing covariate ( $n$ 6202) or dietary information ( $n$ 2537) and missing information on diabetes at follow-up or baseline ( $n$ 10), leaving 36256 men and 39256 women. Study protocols were approved by the Committee on Human Studies at the University of Hawaii and by the Institutional Review Board of Kaiser Permanente.

\section{Data assessment}

Incident cases of diabetes mellitus were identified by selfreport in a follow-up questionnaire mailed to the participants between 1999 and 2003 (response rate in Hawaii $88 \%$ ), or via a medication questionnaire (including diabetes drugs) administered to $38 \%$ of the MEC participants who agreed to a blood draw between 2001 and 2007, or by a linkage in 2007 with the two major health plans in Hawaii, Kaiser Permanente and Blue Cross/Blue Shield, that cover $90 \%$ of the population in Hawaii ${ }^{(2)}$. After excluding 812 self-reported cases not confirmed by a health plan, a total of 8587 incident cases were identified during a median follow-up time of 13.5 years: 2251 from the follow-up questionnaire, 996 from the medication questionnaire and 5340 through the health plans. Information on vital status of all participants is updated annually by linkage with state and national death certificates.

Dietary data were collected at baseline by a validated quantitative FFQ specifically designed for use in this multiethnic population ${ }^{(5)}$. Nutrient intake was determined by linking food intake to an ethnic-specific food composition database developed and maintained at the Cancer Research Center of Hawaii. In a validation and calibration sub-study average correlation coefficients ranged from 0.26 to 0.57 for nutrients and from 0.57 to 0.75 for nutrient densities for the different sex-ethnic groups, indicating good validity ${ }^{(6)}$.

Food group intake was calculated as grams per day of the basic food commodities and covered single food items as well as mixed dishes. Intakes were converted to energy densities (g/4184kJ per d). Food groups examined for the current analysis were red meat (beef, pork and lamb), fresh poultry, processed red meat and processed poultry.

\section{Statistical analysis}

We applied Cox proportional hazard regression with follow-up time as the underlying time metric and stratified by age at cohort entry to estimate hazard ratios (HR) and $95 \%$ confidence intervals for sex-specific quintiles of meat consumption. Linear trend tests were performed using an ordinal variable representing the median of each quintile. Follow-up time was calculated as the difference between date of cohort entry and date of diabetes diagnosis, date of death or last date when data on diabetes status were available, whichever came first ${ }^{(2)}$. The final models were adjusted for ethnicity, BMI, physical activity, education and energy intake (log-transformed). We tested for interaction of meat consumption and ethnicity and additionally calculated ethnic-specific HR of diabetes for meat consumption. No major violations of the proportional hazards assumption were observed when examined with time-dependent explanatory variables. All statistical analyses were performed using the SAS statistical software package version $9 \cdot 2$ (SAS Institute Inc., Cary, NC, USA).

\section{Results}

The median intake of beef or fresh poultry did not differ by ethnicity, but higher amounts of pork, red meat and processed red meat were consumed by Native Hawaiians, while Caucasians tended to consume least of these meat groups (Table 1).

Red meat and processed red meat were positively associated with diabetes risk in men (Table 2). The HR comparing extreme quintiles was 1.43 (95\% CI 1.29 , 1.59) for red meat and 1.57 (95\% CI 1.42, 1.75) for processed red meat in multivariate-adjusted models. When we excluded BMI from the model, the HR for comparing extreme quintiles was 1.70 (95\% CI 1.54, 1.88) for red meat and $1.92(95 \%$ CI $1.73,2 \cdot 13)$ for processed meat. Further adjustment for fibre intake, which was recently shown to be associated with diabetes in this cohort, attenuated this association slightly with HR of $1 \cdot 38$ (95\% CI $1 \cdot 24,1 \cdot 53)$ for red meat and 1.53 (95\% CI $1 \cdot 37,1 \cdot 71)$ for processed red meat comparing highest $v$. lowest quintile (data not shown). Intake of fresh poultry was not associated with diabetes risk although HR for the second, third and fourth quintiles were slightly increased. Intake of processed poultry increased risk by $30 \%$ for the highest intake quintile compared with the lowest.

Similar associations between meat intake and diabetes risk were found in women (Table 3), although the risk estimates tended to be lower than in men. HR for diabetes comparing the highest $v$. lowest intake quintile was $1 \cdot 30$ (95\% CI $1 \cdot 17,1.45)$ for red meat and 1.45 (95\% CI 1.30 , 1.62 ) for processed red meat. Without adjustment for BMI, the respective HR was 1.67 (95\% CI 1.50, 1.86) and 1.84 (95\% CI 1.65, 2.06). Additional adjustment for fibre intake did not alter the multivariate-adjusted estimates: $\mathrm{HR}=1 \cdot 29$ (95\% CI 1.15, 1.45) for red meat and HR $=1.45$ (95\% CI $1 \cdot 30,1.65)$ for processed red meat (data not shown). Fresh poultry intake was not associated with diabetes, but women in the fifth quintile of processed poultry intake had a $23 \%$ higher diabetes risk compared with the lowest quintile.

Associations for the fifth $v$. the first meat intake quintile stratified by ethnicity are shown in Fig. 1 for men and Fig. 2 for women. In men, the tests for interaction between ethnicity and red meat intake $\left(P_{\text {interaction }}=0.006\right)$ and processed red meat intake $\left(P_{\text {interaction }}=0.002\right)$ were significant, with a slightly higher risk for Caucasians and a lower risk for Japanese-Americans. We did not find a significant interaction for fresh $\left(P_{\text {interaction }}=0 \cdot 47\right)$ or processed poultry $\left(P_{\text {interaction }}=0 \cdot 46\right)$ in men or for any meat type in women $\left(P_{\text {interaction }}=0.47\right.$ for processed red meat, 0.32 for 
Table 1 Baseline characteristics of participants in the Hawaii component of the Multiethnic Cohort by ethnicity and sex, 1993-2007

\begin{tabular}{|c|c|c|c|c|c|c|c|c|c|c|c|c|}
\hline & \multicolumn{6}{|c|}{ Men } & \multicolumn{6}{|c|}{ Women } \\
\hline & \multicolumn{2}{|c|}{$\begin{array}{l}\text { Caucasian } \\
(n 15116)\end{array}$} & \multicolumn{2}{|c|}{$\begin{array}{l}\text { Native Hawaiian } \\
\quad(n \text { 4568) }\end{array}$} & \multicolumn{2}{|c|}{$\begin{array}{l}\text { Japanese-American } \\
\quad(n \text { 16572) }\end{array}$} & \multicolumn{2}{|c|}{$\begin{array}{l}\text { Caucasian } \\
(n 14643)\end{array}$} & \multicolumn{2}{|c|}{$\begin{array}{l}\text { Native Hawaiian } \\
\quad(n \text { 5941) }\end{array}$} & \multicolumn{2}{|c|}{$\begin{array}{c}\text { Japanese-American } \\
(n \text { 18672) }\end{array}$} \\
\hline & $n$ & $\%$ & $n$ & $\%$ & $n$ & $\%$ & $n$ & $\%$ & $n$ & $\%$ & $n$ & $\%$ \\
\hline \multicolumn{13}{|l|}{ Age (years) } \\
\hline $45-54$ & 6766 & $44 \cdot 8$ & 2305 & $50 \cdot 5$ & 5437 & $32 \cdot 8$ & 6901 & $47 \cdot 1$ & 3158 & $53 \cdot 2$ & 6058 & $32 \cdot 4$ \\
\hline $55-64$ & 4194 & $27 \cdot 8$ & 1334 & $29 \cdot 2$ & 4645 & $28 \cdot 0$ & 3909 & $26 \cdot 7$ & 1678 & $28 \cdot 2$ & 5686 & $30 \cdot 5$ \\
\hline$\geq 65$ & 4156 & $27 \cdot 5$ & 929 & $20 \cdot 3$ & 6490 & $39 \cdot 2$ & 3833 & $26 \cdot 2$ & 1105 & $18 \cdot \overline{6}$ & 6928 & $37 \cdot 1$ \\
\hline \multicolumn{13}{|l|}{ Diabetes status } \\
\hline Non-case & 14036 & $92 \cdot 9$ & 3770 & $82 \cdot 5$ & 13895 & $83 \cdot 9$ & 13928 & $95 \cdot 1$ & 4998 & $84 \cdot 1$ & 16298 & $87 \cdot 3$ \\
\hline Incident case & 1080 & $7 \cdot 1$ & 798 & $17 \cdot 5$ & 2677 & $16 \cdot 2$ & 715 & 4.9 & 943 & $15 \cdot 9$ & 2374 & $12 \cdot 7$ \\
\hline \multicolumn{13}{|l|}{ Education (years) } \\
\hline$\leq 12$ & 2870 & $19 \cdot 0$ & 2172 & $47 \cdot 6$ & 6472 & $39 \cdot 1$ & 3398 & $23 \cdot 2$ & 3115 & $52 \cdot 4$ & 7691 & $41 \cdot 2$ \\
\hline $13-15$ & 4377 & $29 \cdot 0$ & 1456 & $31 \cdot 9$ & 4777 & $28 \cdot 8$ & 5023 & $34 \cdot 3$ & 1789 & $30 \cdot 1$ & 5255 & $28 \cdot 1$ \\
\hline \multirow{2}{*}{\multicolumn{13}{|c|}{ BMI $\left(\mathrm{kg} / \mathrm{m}^{2}\right)$}} \\
\hline & & & & & & & & & & & & \\
\hline$<22$ & 2047 & $13 \cdot 5$ & 318 & $7 \cdot 0$ & 3107 & $18 \cdot 8$ & 4965 & 33.9 & 969 & $16 \cdot 3$ & 8040 & $43 \cdot 1$ \\
\hline $22-<25$ & 5080 & $33 \cdot 6$ & 900 & $19 \cdot 7$ & 6439 & $38 \cdot 9$ & 4180 & $28 \cdot 6$ & 1321 & $22 \cdot 2$ & 5765 & $30 \cdot 9$ \\
\hline $25-<30$ & 6135 & $40 \cdot 6$ & 2019 & $44 \cdot 2$ & 6084 & $36 \cdot 7$ & 3670 & $25 \cdot 1$ & 1985 & $33 \cdot 4$ & 4002 & $21 \cdot 4$ \\
\hline \multirow[t]{2}{*}{$\geq 30$} & 1854 & $12 \cdot 3$ & 1331 & $29 \cdot 1$ & 942 & $5 \cdot 7$ & 1828 & $12 \cdot 5$ & 1666 & $28 \cdot 0$ & 865 & $4 \cdot 6$ \\
\hline & Median & IQR & Median & IQR & Median & IQR & Median & IQR & Median & IQR & Median & IQR \\
\hline Total energy (kJ/d) & 9251 & 7167,11899 & 10724 & 7853,14523 & 9155 & 7155,11611 & 7339 & 5720,9422 & 8786 & 6406,12083 & 7289 & 5699,9318 \\
\hline Red meat* ${ }^{*}$ & $16 \cdot 5$ & $9 \cdot 3,24 \cdot 7$ & $19 \cdot 9$ & $13 \cdot 2,27 \cdot 8$ & $17 \cdot 4$ & $10 \cdot 5,25 \cdot 0$ & $12 \cdot 8$ & $6 \cdot 5,20 \cdot 7$ & $18 \cdot 1$ & $11 \cdot 5,26 \cdot 2$ & $14 \cdot 7$ & $8 \cdot 7,22 \cdot 0$ \\
\hline Processed red meat ${ }^{*}$ & $6 \cdot 4$ & $3 \cdot 2,10 \cdot 7$ & $9 \cdot 3$ & $5 \cdot 6,13 \cdot 8$ & $8 \cdot 2$ & $4 \cdot 7,12 \cdot 3$ & $4 \cdot 1$ & $1 \cdot 9,7 \cdot 6$ & $7 \cdot 5$ & $4 \cdot 1,11 \cdot 8$ & $6 \cdot 2$ & $3 \cdot 2,9 \cdot 9$ \\
\hline Fresh poultry* & $14 \cdot 4$ & $8 \cdot 7,22 \cdot 2$ & $14 \cdot 3$ & $9 \cdot 1,21 \cdot 6$ & $15 \cdot 0$ & $9 \cdot 7,22 \cdot 0$ & $15 \cdot 2$ & $8 \cdot 9,24 \cdot 3$ & $15 \cdot 1$ & $9 \cdot 7,22 \cdot 7$ & $15 \cdot 5$ & $10 \cdot 0,22 \cdot 8$ \\
\hline Processed poultry ${ }^{*}$ & 0.5 & $0 \cdot 1,1 \cdot 6$ & 0.7 & $0 \cdot 1,1 \cdot 6$ & $0 \cdot 6$ & $0 \cdot 1,1 \cdot 3$ & 0.3 & $0 \cdot 1,1 \cdot 2$ & 0.6 & $0 \cdot 1,1 \cdot 3$ & 0.4 & $0 \cdot 1,1 \cdot 1$ \\
\hline Beef* $^{\star}$ & $12 \cdot 2$ & $6 \cdot 9,18 \cdot 4$ & $12 \cdot 9$ & $8 \cdot 1,18 \cdot 4$ & $11 \cdot 7$ & $7 \cdot 0,17 \cdot 2$ & $9 \cdot 5$ & $4 \cdot 8,15 \cdot 4$ & $11 \cdot 9$ & $7 \cdot 2,17 \cdot 3$ & $9 \cdot 8$ & $5 \cdot 6,14 \cdot 8$ \\
\hline Pork* ${ }^{*}$ & 3.0 & $1 \cdot 1,5 \cdot 7$ & $6 \cdot 1$ & $3 \cdot 6,8 \cdot 8$ & $4 \cdot 8$ & $2 \cdot 5,7 \cdot 6$ & $2 \cdot 3$ & $0 \cdot 7,4 \cdot 8$ & $5 \cdot 4$ & $3 \cdot 0,8 \cdot 1$ & $4 \cdot 2$ & $2 \cdot 2,6 \cdot 8$ \\
\hline Dietary fibre* & $10 \cdot 3$ & $8 \cdot 0,13 \cdot 1$ & $8 \cdot 1$ & $6 \cdot 3,10 \cdot 6$ & $8 \cdot 7$ & $6 \cdot 7,11 \cdot 4$ & $12 \cdot 0$ & $9 \cdot 5,15 \cdot 2$ & $10 \cdot 1$ & $7 \cdot 8,13 \cdot 2$ & $11 \cdot 3$ & $8 \cdot 8,14 \cdot 2$ \\
\hline Physical activity (METS) & $1 \cdot 6$ & $1 \cdot 4,1 \cdot 8$ & $1 \cdot 7$ & $1.5,1.9$ & $1 \cdot 6$ & $1 \cdot 5,1 \cdot 8$ & $1 \cdot 6$ & $1 \cdot 4,1 \cdot 8$ & $1 \cdot 6$ & $1 \cdot 4,1 \cdot 8$ & $1 \cdot 6$ & $1 \cdot 4,1 \cdot 7$ \\
\hline
\end{tabular}

IQR, interquartile range; METS, metabolic equivalent of tasks.

${ }^{*}$ Nutrient intakes in $\mathrm{g} / 4184 \mathrm{~kJ}$ per $\mathrm{d}$. 
Table 2 Diabetes risk as hazard ratio (HR) and $95 \%$ confidence interval associated with quintiles of meat consumption in men, Hawaii component of the Multiethnic Cohort Study, 1993-2007

\begin{tabular}{|c|c|c|c|c|c|c|}
\hline & \multicolumn{5}{|c|}{ Quintile of intake } & \multirow[b]{2}{*}{$P_{\text {trend }}$} \\
\hline & 1 & 2 & 3 & 4 & 5 & \\
\hline Red meat intake* & $5 \cdot 43$ & $12 \cdot 63$ & $18 \cdot 47$ & $25 \cdot 04$ & $35 \cdot 63$ & \\
\hline No. of cases & 690 & 880 & 1034 & 1077 & 874 & \\
\hline Person-years & 95770 & 91300 & 89399 & 83708 & 66739 & \\
\hline Adjusted HRt & 1.00 & $1 \cdot 17$ & $1 \cdot 31$ & 1.42 & $1 \cdot 43$ & \\
\hline $95 \% \mathrm{Cl}$ & - & $1 \cdot 06,1 \cdot 29$ & $1 \cdot 19,1 \cdot 44$ & $1 \cdot 29,1 \cdot 56$ & $1 \cdot 29,1 \cdot 59$ & $<0.0001$ \\
\hline Processed red meat intake ${ }^{\star}$ & $1 \cdot 68$ & $4 \cdot 64$ & $7 \cdot 49$ & $10 \cdot 91$ & $17 \cdot 08$ & \\
\hline No. of cases & 537 & 746 & 930 & 1161 & 1181 & \\
\hline Person-years & 86251 & 83816 & 87706 & 90242 & 78902 & \\
\hline Adjusted HRt & 1.00 & $1 \cdot 22$ & $1 \cdot 30$ & 1.45 & 1.57 & \\
\hline $95 \% \mathrm{Cl}$ & - & $1 \cdot 09,1 \cdot 37$ & $1 \cdot 17,1 \cdot 45$ & $1 \cdot 31,1 \cdot 61$ & $1 \cdot 42,1 \cdot 75$ & $<0.0001$ \\
\hline Fresh poultry intake* & $5 \cdot 98$ & $11 \cdot 65$ & $16 \cdot 83$ & $23 \cdot 60$ & $38 \cdot 18$ & \\
\hline No. of cases & 986 & 1087 & 1029 & 867 & 586 & \\
\hline Person-years & 102773 & 100315 & 91370 & 77595 & 54864 & \\
\hline Adjusted HR† & $1 \cdot 00$ & 1.05 & $1 \cdot 10$ & $1 \cdot 11$ & 1.06 & \\
\hline $95 \% \mathrm{Cl}$ & - & $0 \cdot 96,1 \cdot 15$ & $1 \cdot 01,1 \cdot 20$ & $1 \cdot 01,1 \cdot 21$ & $0 \cdot 96,1 \cdot 18$ & $0 \cdot 19$ \\
\hline Processed poultry intake* & 0.00 & $0 \cdot 11$ & 0.53 & $1 \cdot 20$ & $2 \cdot 85$ & \\
\hline No. of cases & 543 & 987 & 968 & 1100 & 957 & \\
\hline Person-years & 69649 & 94286 & 90077 & 91979 & 80926 & \\
\hline Adjusted HRt & 1.00 & $1 \cdot 19$ & $1 \cdot 19$ & $1 \cdot 27$ & $1 \cdot 30$ & \\
\hline $95 \% \mathrm{Cl}$ & - & $1 \cdot 07,1 \cdot 32$ & $1 \cdot 07,1 \cdot 32$ & $1 \cdot 14,1 \cdot 40$ & $1 \cdot 17,1 \cdot 44$ & 0.0001 \\
\hline
\end{tabular}

${ }^{*}$ Median intake in $\mathrm{g} / 4184 \mathrm{~kJ}$ per $\mathrm{d}$.

tHR adjusted for ethnicity, education, BMI, physical activity and total energy intake (log-transformed) as well as stratified by age at cohort entry.

Table 3 Diabetes risk as hazard ratio (HR) and $95 \%$ confidence interval associated with quintiles of meat consumption in women, Hawaii component of the Multiethnic Cohort Study, 1993-2007

\begin{tabular}{|c|c|c|c|c|c|c|}
\hline & \multicolumn{5}{|c|}{ Quintile of intake } & \multirow[b]{2}{*}{$P_{\text {trend }}$} \\
\hline & 1 & 2 & 3 & 4 & 5 & \\
\hline Red meat intake* & 3.99 & $9 \cdot 89$ & $15 \cdot 32$ & $21 \cdot 54$ & $31 \cdot 78$ & \\
\hline No. of cases & 570 & 745 & 865 & 974 & 878 & \\
\hline Person-years & 103951 & 104175 & 100031 & 97159 & 80773 & \\
\hline Adjusted HRt & $1 \cdot 00$ & $1 \cdot 06$ & $1 \cdot 17$ & $1 \cdot 25$ & $1 \cdot 30$ & \\
\hline $95 \% \mathrm{Cl}$ & - & $0 \cdot 95,1 \cdot 18$ & $1 \cdot 06,1 \cdot 31$ & $1 \cdot 13,1 \cdot 39$ & $1 \cdot 17,1 \cdot 45$ & $<0.0001$ \\
\hline Processed red meat intake* & 1.05 & $3 \cdot 12$ & $5 \cdot 42$ & $8 \cdot 46$ & $13 \cdot 86$ & \\
\hline No. of cases & 465 & 635 & 792 & 1027 & 1113 & \\
\hline Person-years & 97302 & 95474 & 97422 & 102005 & 93885 & \\
\hline Adjusted HRt & $1 \cdot 00$ & $1 \cdot 20$ & $1 \cdot 24$ & $1 \cdot 37$ & $1 \cdot 45$ & \\
\hline $95 \% \mathrm{Cl}$ & - & $1 \cdot 07,1 \cdot 35$ & $1 \cdot 10,1 \cdot 39$ & $1 \cdot 22,1 \cdot 53$ & $1 \cdot 30,1 \cdot 62$ & $<0.0001$ \\
\hline Fresh poultry intake* & $6 \cdot 46$ & $12 \cdot 65$ & $18 \cdot 37$ & $26 \cdot 40$ & $43 \cdot 24$ & \\
\hline No. of cases & 912 & 1050 & 977 & 697 & 396 & \\
\hline Person-years & 126807 & 119115 & 103289 & 83881 & 52998 & \\
\hline Adjusted HRt & $1 \cdot 00$ & $1 \cdot 12$ & $1 \cdot 18$ & 1.09 & $1 \cdot 01$ & \\
\hline $95 \% \mathrm{Cl}$ & - & $1 \cdot 02,1 \cdot 22$ & $1 \cdot 07,1 \cdot 29$ & $0 \cdot 98,1 \cdot 20$ & $0 \cdot 90,1 \cdot 14$ & 0.95 \\
\hline Processed poultry intake ${ }^{\star}$ & 0.00 & $0 \cdot 10$ & 0.42 & 1.06 & $2 \cdot 42$ & \\
\hline No. of cases & 496 & 884 & 892 & 990 & 770 & \\
\hline Person-years & 83890 & 107572 & 105903 & 105656 & 83068 & \\
\hline Adjusted HR† & $1 \cdot 00$ & $1 \cdot 19$ & $1 \cdot 18$ & $1 \cdot 20$ & $1 \cdot 23$ & \\
\hline $95 \% \mathrm{Cl}$ & - & $1 \cdot 06,1 \cdot 32$ & $1 \cdot 06,1 \cdot 32$ & $1 \cdot 08,1 \cdot 34$ & $1 \cdot 10,1 \cdot 38$ & 0.03 \\
\hline
\end{tabular}

*Median intake in $\mathrm{g} / 4184 \mathrm{~kJ}$ per $\mathrm{d}$.

tHR adjusted for ethnicity, education, BMI, physical activity and total energy intake (log-transformed) as well as stratified by age at cohort entry.

fresh poultry and $0 \cdot 24$ for processed poultry), except for consumption of red meat with a borderline significant interaction $\left(P_{\text {interaction }}=0 \cdot 05\right)$.

\section{Discussion}

In the current analysis of the Hawaii component of the MEC, we found a positive association between intakes of red meat, processed red meat and processed poultry with risk of diabetes in men and women independent of BMI status. Fresh poultry consumption was not associated with diabetes risk.

Strengths of the present study are the large sample size, the prospective design with long follow-up time, and the extensive data collection allowing adjustment for a variety of known confounders such as BMI. However, the possibility of residual confounding cannot be excluded. 


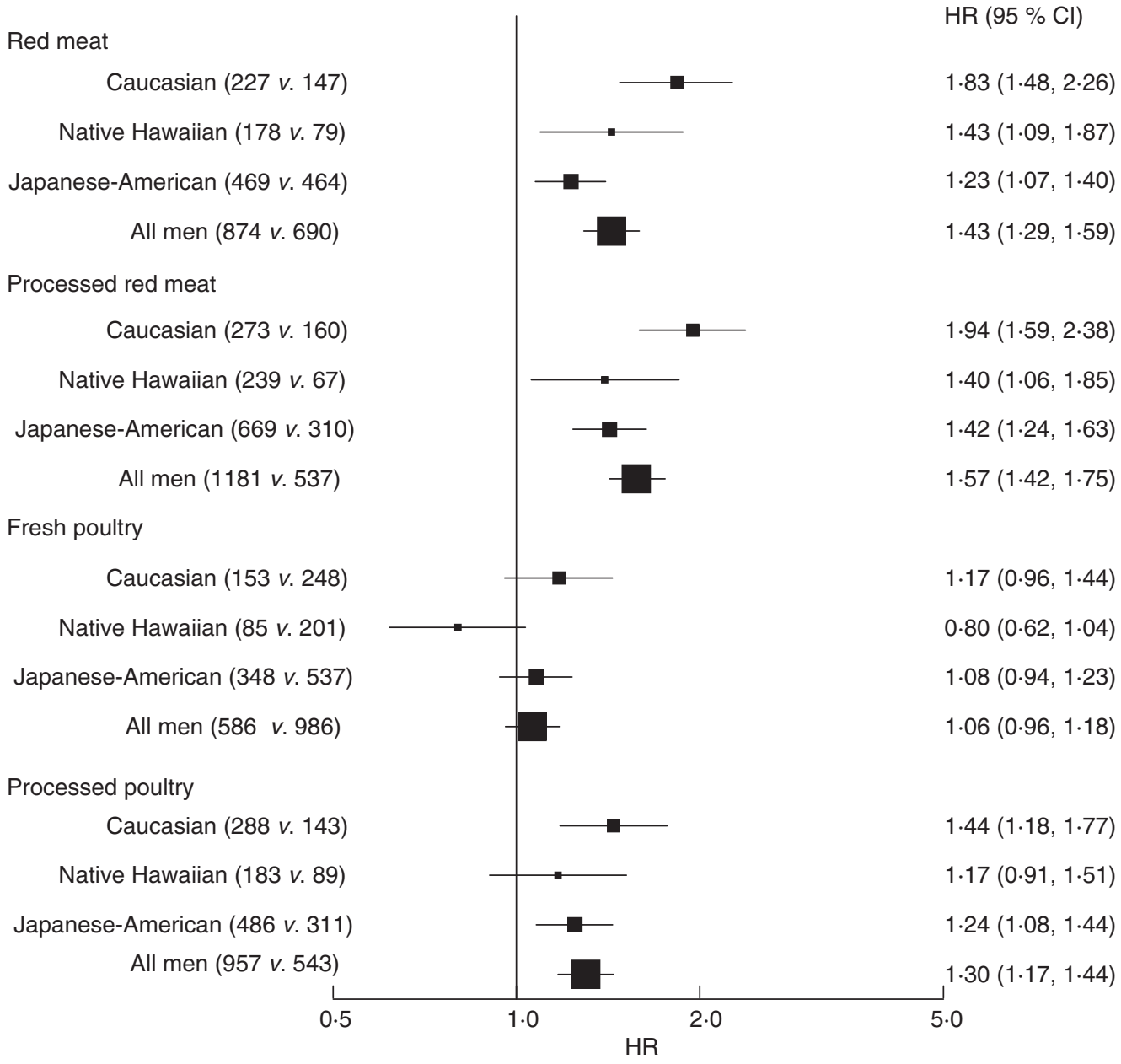

Fig. 1 Diabetes risk (hazard ratio (HR) and $95 \%$ confidence interval) comparing highest $v$. lowest quintile of meat consumption by ethnicity in men, Hawaii component of the Multiethnic Cohort Study, 1993-2007. HR adjusted for education, BMI, physical activity and total energy intake (log-transformed) as well as stratified by age at cohort entry; numbers in parentheses represent the number of diabetes cases in the highest $v$. lowest quintile of meat consumption

The study FFQ was specifically designed for use in this multiethnic cohort, and reproducibility and validity of nutrient intake densities were found to be satisfactory and comparable to those of other similar studies ${ }^{(6)}$. Moreover, mixed dishes containing meat were disaggregated into their component ingredients and considered in the estimation of total meat intake. However, misreporting of certain foods might have biased our results, although due to the prospective design, disease status could not have influenced reporting of meat intake. Since we did not have repeat measurements of diet, changes in diet over time could not be considered in the analysis. Furthermore, we were not able to distinguish the effect of meat from intakes of its major constituents, such as animal fat, animal protein and haem Fe. Although diabetes status was ascertained by several questionnaires and linkage with health plans, information on type of diabetes was not available; however, given the median age of 59 years of the participants at baseline, more than $90 \%$ of cases were likely to have had type 2 diabetes. Despite the comprehensive case identification approach, some MEC participants may have diabetes that has not been detected yet.

Our results agree with several prospective studies on meat intake and diabetes risk. In a recent meta-analysis ${ }^{(4)}$, the summary risks comparing high $v$. low intake were $1 \cdot 21(95 \%$ CI $1 \cdot 07,1 \cdot 38)$ for red meat and 1.41 (95\% CI $1 \cdot 25,1 \cdot 60)$ for processed meat. The magnitude of these estimates corresponds well with those from our study, although caution is needed for such comparisons due to different units in exposure measurement. Furthermore, the type of red meat consumed (i.e. beef or pork) and the proportion of poultry in comparison to red meat intake likely differs among countries. For example, in a Finnish study $^{(7)}$, intakes of red meat (mean intake in non-cases: $79.6 \mathrm{~g} / \mathrm{d})$ and processed meat $(52.0 \mathrm{~g} / \mathrm{d})$ were considerably higher than poultry intake $(2.6 \mathrm{~g} / \mathrm{d})$, while intakes of poultry and red meat were nearly equal in our study.

A few studies have examined the association between intake of fresh poultry and diabetes risk, with one reporting no association ${ }^{(8)}$ and several others observing 
Red meat

Caucasian (139 v. 110)

Native Hawaiian (284 v. 84)

Japanese-American (455 v . 376)

All women (878 v. 570)

Processed red meat

Caucasian (152 v. 119)

Native Hawaiian (333 v. 63)

Japanese-American (628 v. 283)

All women (1113 v. 465)

Fresh poultry

Caucasian (79 v. 170)

Native Hawaiian (93 v. 241)

Japanese-American (224 v. 501)

All women (396 v. 912)

Processed poultry

Caucasian (171 v. 98)

Native Hawaiian (204 v. 100)

Japanese-American (395 v. 298)

All women (770 v. 496)

0.5

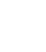
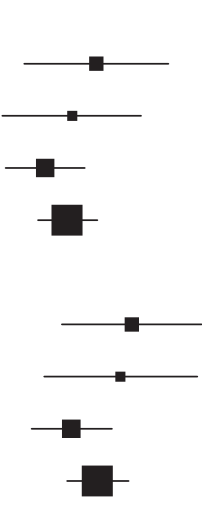

$1.64(1.28,2 \cdot 11)$

$1.57(1.19,2.07)$

$1.32(1.14,1.53)$

$1.45(1.30,1.62)$

$0.93(0.71,1.22)$

$0.97(0.76,1.24)$

$1.04(0.89,1.22)$

$1.01(0.90,1.14)$

$1.34(1.04,1.72)$

$1.13(0.89,1.44)$

$1.23(1.06,1.44)$

$1.23(1.10,1.38)$

HR

Fig. 2 Diabetes risk (hazard ratio (HR) and $95 \%$ confidence interval) comparing highest $v$. lowest quintile of meat consumption by ethnicity in women, Hawaii component of the Multiethnic Cohort Study, 1993-2007. HR adjusted for education, BMI, physical activity and total energy intake (log-transformed) as well as stratified by age at cohort entry; numbers in parentheses represent the number of diabetes cases in the highest $v$. lowest quintile of meat consumption

an inverse association ${ }^{(7,9,10)}$. The slightly elevated risk for the second, third and fourth intake quintile might be due to chance, errors in intake measurements and close correlation between the different types of meat intake. To our knowledge, no other study has examined the association between intake of processed poultry and diabetes.

In an earlier analysis of the MEC, we found an inverse association between dietary fibre intake and diabetes risk in men but not in women ${ }^{(11)}$. As red meat and processed red meat were negatively correlated with fibre intake, we additionally adjusted the present analysis for fibre intake to exclude the possibility of confounding. The HR for red and processed meat in men decreased slightly but remained significant, indicating an effect of meat irrespective of fibre intake. Nevertheless, one has to consider that the positive association of meat consumption and diabetes risk might not be attributable to meat intake per se, but rather to a dietary pattern like the so-called 'Western' pattern, which combines high meat intake, especially processed red meat and processed poultry, with refined grains and sweets ${ }^{(12)}$.

We found no strong indication for effect modification by ethnicity. Tests for interaction were statistically significant only for red and processed red meat consumption in men, which might be explained by ethnically different meat preparation practices or differences in the choice of red meat types. However, the HR for the three ethnic groups did not differ meaningfully and thus the statistical significance might be driven more by the large sample size or the small standard deviations than an underlying biological difference.

One hypothesis for a role of meat intake in diabetes aetiology is that meat consumption increases fat intake, especially saturated fat intake, and thus might act indirectly by increasing body weight, an established risk factor for diabetes ${ }^{(3)}$. Our analysis without adjustment for BMI supported this hypothesis. However, when adjusting for BMI, we still found a significant positive association, indicating that other mechanisms might be important. For example, heating foods such as meat can lead to high levels of advanced glycation end-products, which have been associated with inflammatory responses in human subjects $^{(13)}$. Red meat is a source of haem Fe; higher body Fe stores might impair insulin sensitivity ${ }^{(14)}$ and increase the risk of diabetes ${ }^{(15)}$ by promoting oxidative stress causing tissue damage ${ }^{(16)}$. Processed meat might contain 
preservatives, additives or other chemicals, such as nitrates, nitrites and heterocyclic amines, formed during food preparation. Nitrites, for example, might be converted to nitrosamines, which exert pancreatic $\beta$-cell toxicity ${ }^{(17)}$. Unfortunately, we had no data on food preservation methods to perform separate analysis for these compounds.

In conclusion, our findings add to the growing evidence for a positive association of red meat and processed meat intake with diabetes risk. We found this association to be consistent over the different ethnic strata of the MEC, despite the higher incidence rates of diabetes in Native Hawaiians and Japanese-Americans compared with Caucasians. Besides the known role of body weight, these results highlight the importance of diet and food choices in diabetes aetiology.

\section{Acknowledgements}

Sources of funding: The Multiethnic Cohort is supported by NCI grant R37CA54281 (Principal Investigator: Dr L.N. Kolonel). The recruitment of Native Hawaiians was funded by grant DAMD 17-94-T-4184 (Principal Investigator: Dr A. Nomura). The diabetes project is funded by R21 DK073816 (Principal Investigator: Dr G. Maskarinec). Conflicts of interest: The authors declare that there is no conflict of interest associated with this manuscript. Authorship contributions: All authors made substantial contributions to conception and design, acquisition, analysis or interpretation of data, have been part of writing or critically reviewing the article, and approved the final version. Acknowledgements: We thank Mark M. Schmidt and Aileen Uchida at Kaiser Permanente Center for Health Research, Honolulu, HI and Deborah Taira Juarez and Krista Hodges at HMSA, Blue Cross Blue Shield of Hawaii for their assistance in linking the cohort with the health plans.

\section{References}

1. McNeely MJ \& Boyko EJ (2004) Type 2 diabetes prevalence in Asian Americans: results of a national health survey. Diabetes Care 27, 66-69.
2. Maskarinec G, Erber E, Grandinetti A et al. (2009) Diabetes incidence based on linkages with health plans: the Multiethnic Cohort. Diabetes 58, 1732-1738.

3. Adeghate E, Schattner P \& Dunn E (2006) An update on the etiology and epidemiology of diabetes mellitus. Ann $N Y$ Acad Sci 1084, 1-29.

4. Aune D, Ursin G \& Veierod MB (2009) Meat consumption and the risk of type 2 diabetes: a systematic review and meta-analysis of cohort studies. Diabetologia 52, 2277-2287.

5. Kolonel LN, Henderson BE, Hankin JH et al. (2000) A multiethnic cohort in Hawaii and Los Angeles: baseline characteristics. Am J Epidemiol 151, 346-357.

6. Stram DO, Hankin JH, Wilkens LR et al. (2000) Calibration of the dietary questionnaire for a multiethnic cohort in Hawaii and Los Angeles. Am J Epidemiol 151, 358-370.

7. Montonen J, Jarvinen R, Heliovaara M et al. (2005) Food consumption and the incidence of type II diabetes mellitus. Eur J Clin Nutr 59, 441-448.

8. van Dam RM, Willett WC, Rimm EB et al. (2002) Dietary fat and meat intake in relation to risk of type 2 diabetes in men. Diabetes Care 25, 417-424.

9. Villegas R, Shu XO, Gao YT et al. (2006) The association of meat intake and the risk of type 2 diabetes may be modified by body weight. Int J Med Sci 3, 152-159.

10. Schulze MB, Manson JE, Willett WC et al. (2003) Processed meat intake and incidence of type 2 diabetes in younger and middle-aged women. Diabetologia 46, 1465-1473.

11. Hopping BN, Erber E, Grandinetti A et al. (2010) Dietary fiber, magnesium, and glycemic load alter risk of type 2 diabetes in a multiethnic cohort in Hawaii. J Nutr 140, 68-74.

12. Erber E, Hopping BN, Grandinetti A et al. (2010) Dietary patterns and risk for diabetes: the Multiethnic Cohort. Diabetes Care 33, 532-538.

13. Uribarri J, Cai W, Sandu O et al. (2005) Diet-derived advanced glycation end products are major contributors to the body's AGE pool and induce inflammation in healthy subjects. Ann N Y Acad Sci 1043, 461-466.

14. Hua NW, Stoohs RA \& Facchini FS (2001) Low iron status and enhanced insulin sensitivity in lacto-ovo vegetarians. Br J Nutr 86, 515-519.

15. Salonen JT, Tuomainen TP, Nyyssonen K et al. (1998) Relation between iron stores and non-insulin dependent diabetes in men: case-control study. BMJ 317, 727-730.

16. Wolff SP (1993) Diabetes mellitus and free radicals. Free radicals, transition metals and oxidative stress in the aetiology of diabetes mellitus and complications. $\mathrm{Br}$ Med Bull 49, 642-652.

17. LeDoux SP, Woodley SE, Patton NJ et al. (1986) Mechanisms of nitrosourea-induced $\beta$-cell damage. Alterations in DNA. Diabetes 35, 866-872. 